\title{
When Resistance Is Futile: Consequences of Failed Counterarguing for Attitude Certainty
}

\author{
Derek D. Rucker and Richard E. Petty \\ Ohio State University
}

\begin{abstract}
This research tests the notion that attitudes after a failed attempt to counterargue may be stronger than attitudes after undirected thinking. Specifically, failed counterarguing may be accompanied by unique metacognitions that serve to strengthen the attitude. The present research examines this issue by giving participants a very strong message and instructing them to counterargue or simply think about the message. Across several experiments, attitudes were as favorable when individuals were trying to counterargue as when they were simply thinking, indicating that counterarguing failed to instill any extra resistance. However, attitudes were held with greater certainty following failed counterarguing compared with following undirected thinking. Furthermore, attitudes following failed counterarguing were more predictive of subsequent behavioral intentions. The metacognitions that follow failed counterarguing are addressed.
\end{abstract}

Currently popular models of persuasion such as the elaboration likelihood model (ELM; Petty \& Cacioppo, 1986; Petty \& Wegener, 1999) and the heuristic systematic model (HSM; Chaiken, Liberman, \& Eagly, 1989; Chen \& Chaiken, 1999) recognize that people can process the same message differently. For example, some individuals might be relatively undirected in their thinking and focus on whatever thoughts naturally come to mind. Alternatively, other individuals might be directed in their thinking and focus their efforts on trying to adopt or refute a message position (Kruglanski, 1996; Kunda, 1990; Lord, Ross, \& Lepper, 1979).

In the current research, we focus on attitudes that follow from a failed attempt at counterarguing. We compare these attitudes to those that result from relatively undirected thinking. ${ }^{1}$ We hypothesize that in situations where both types of thinking lead to equivalent levels of agreement with the message, the act of attempting to counterargue, but failing, will have unique consequences for the certainty with which people hold their attitudes. Furthermore, this difference in certainty is proposed to be a result of the metacognitions that stem from unsuccessful counterarguing versus undirected thinking. Before explaining our attitude certainty hypothesis and delving further into this topic, we review what is known about counterarguing.

\section{The Effects of Counterarguing on Postmessage Attitudes}

Counterarguing is a thought process that can inhibit agreement with an advocated position. For example, variables that have been

This research was supported by National Institute of Mental Health Individual Training Grant 5F31MH12849-03 to Derek D. Rucker and National Science Foundation Grant BNS 9520157 to Richard E. Petty. We thank members of the 2001-2003 Groups for Attitudes and Persuasion at Ohio State University for very helpful comments on this research.

Correspondence concerning this article should be addressed to Derek D. Rucker or Richard E. Petty, Department of Psychology, Ohio State University, 1885 Neil Avenue, Columbus, OH 43210-1222. E-mail: rucker.46@osu.edu or petty.1@osu.edu shown to increase counterarguing, such as forewarning of persuasive intent (Petty \& Cacioppo, 1979), inoculation (McGuire, 1964; McGuire \& Papageorgis, 1962), instruction to counterargue (Killeya \& Johnson, 1998), reactance (Brehm, 1966, 1972), and high levels of message repetition (Cacioppo \& Petty, 1979), have all been associated with relatively unfavorable attitudes toward an advocated position. Although less agreement often results from counterarguing, this does not mean it is an inevitable outcome. There are often situations in which individuals, despite attempting to counterargue a message, may lack the ability to do so. For example, distraction that is present during a message can prevent people from counterarguing (Petty, Wells, \& Brock, 1976). Or, individual differences such as having insufficient knowledge or experience in defending one's position can hinder counterarguing ability, as illustrated in McGuire's (1964) classic work on cultural truisms. For nontruism topics, perhaps the most obvious reason a nondistracted person might fail in counterarguing is that the message contains such compelling reasons for the advocated position that it is very difficult or impossible to find genuine faults in the arguments. In such situations, attempting to counterargue should not reduce agreement relative to undirected thinking. Thus, counterarguing is a process that can hinder persuasion, but only if successful.

\section{Effects of Successful Versus Failed Counterarguing: A Metacognitive Perspective}

The present research applies a metacognitive framework to understand the consequences of unsuccessful or failed counterar-

\footnotetext{
${ }^{1}$ Individuals can presumably try to refute or resist through other means such as attitude bolstering (Lydon, Zanna, \& Ross, 1988), source derogation (Pratkanis, Greenwald, Leippe, \& Baumgardner, 1988; Zuwerink \& Devine, 1996), and selective avoidance (Frey, 1986; Gilbert, 1993). However, given the dominance of counterarguing in the resistance literature, and the popularity of this in people's naïve theories of resistance (see Jacks \& Cameron, 2003) we focused on this in our initial research.
} 
guing for the certainty with which people hold their attitudes. By failed counterarguing, we mean that following a message in response to which people attempt to counterargue, attitudes are significantly more favorable toward the advocated position than they would have been had the individuals not received the message (i.e., the counterarguing failed to prevent attitude change). Furthermore, these individuals' attitudes are no less favorable than those of people who processed the same message carefully but did not explicitly attempt to counterargue (i.e., the attempt at counterarguing did not inhibit agreement compared with undirected thinking). ${ }^{2}$ By metacognition, we refer to the idea that people can have thoughts about their thoughts or thought processes (see Jost, Kruglanski, \& Nelson, 1998). Emerging work on metacognition in persuasion supports the notion that people can reflect on and think about the thinking they have done in response to a persuasive message (e.g., Petty, Briñol, \& Tormala, 2002). This reflection about one's thoughts can have a unique impact that is separate from the specific thoughts regarding the message itself. For example, recent research on successful counterarguing suggests that when people succeed at resisting a message (i.e., exhibit no attitude change), they reflect on why their resistance attempt was successful (Tormala \& Petty, 2002). Furthermore, this reflection has been shown to have implications for individuals' certainty in their attitudes. It is important to understand the certainty with which attitudes are held because certainty contributes to the overall strength of one's attitudes (Petty \& Krosnick, 1995). Next, we review prior work on successful counterarguing and attitude certainty and discuss the implications failed counterarguing may have for the certainty with which attitudes are held.

\section{Effects of Successful Counterarguing on Attitude Certainty}

Attitude certainty is defined as a subjective feeling of conviction or validity in one's attitude and/or the extent to which an individual believes his or her attitude is correct (Festinger, 1950, 1954; Gross, Holtz, \& Miller, 1995). As a key determinant of attitude strength, increased certainty has been shown to enhance the attitude-behavior relationship (Fazio \& Zanna, 1978), render attitudes more resistant to change (e.g., Bassili, 1996; Krosnick \& Abelson, 1992; Swann, Pelham, \& Chidester, 1988), and produce more persistent attitudes (Bassili, 1996).

Tormala and Petty (2002) found that successfully defending an attitude through counterargumentation led individuals to become more certain of their initial attitudes. Specifically, in a series of studies, Tormala and Petty directed participants to generate counterarguments to a message. In one study, for instance, a message contained a mixture of both strong and weak arguments (so participants would be successful in counterarguing it), but participants were led to believe that the message was strong. Participants who received the message and successfully counterargued the message showed attitudes that were no more favorable toward the advocacy than individuals who did not receive the message, indicating that counterarguing was successful. However, individuals who successfully counterargued the message were more certain of their initial (unchanged) attitudes than were individuals in the nomessage control group.

Tormala and Petty (2002) suggested that people might become more confident in their initial attitudes when they recognize they have successfully counterargued a message perceived to be strong because they can attribute success to the validity of their attitudes (e.g., "I was able to counterargue strong arguments, so my attitude must be right!"). However, if they did not attempt to counterargue the message (the no-message control), certainty is not increased because there is no successful counterarguing to reflect upon. Given that individuals reflect on the implications of successful counterarguing, it seems plausible that individuals might also reflect on the implications of failed counterarguing.

\section{Effects of Failed Counterarguing on Attitude Certainty}

We hypothesize that failed counterarguing may lead to attitudes held with greater certainty compared with attitudes formed by processing the same message without intently focusing on finding faults. Our key hypothesis is that forming or changing one's attitudes, despite a search for fault in a message, may open the gates to metacognitions that do not accompany comparable attitudes that stem from processing that is not focused on finding faults. For example, just as metacognitve inferences may accompany successful counterarguing as a means of explaining that success (e.g., "my initial attitude must be valid"; Tormala \& Petty, 2002), different metacognitive inferences may be associated with failed counterarguing (e.g., "attitudes consistent with the advocated position must be valid"). These inferences about one's success or failure in counterarguing would be less likely to occur when people do not have a counterarguing goal.

In short, we posit that a failed attempt to find fault may lead to enhanced certainty in the new (changed) attitude relative to effortful processing of the same message that is not accompanied by an explicit goal to counterargue. The logic is as follows. For a very compelling message, regardless of whether people simply attempted to think about the message, or attempted to generate negative thoughts, they would presumably generate some favorable thoughts with regard to the advocacy. In both cases, people would be aware that there were positive aspects of the advocacy. However, if an individual engages in an explicit attempt to find fault in a message, but finds that few or no counterarguments come to mind, the person can also conclude that they possess few negative thoughts about the advocacy. That is, individuals can think to themselves, "Because I tried to generate negative thoughts and came up with none (or very few), I now am sure that I have few negative thoughts. Because I have few negative thoughts, I am confident in my new attitude." However, an individual who has not aggressively considered potential faults in a message, but only

\footnotetext{
${ }^{2}$ It is conceptually possible for people who fail to counterargue to have less favorable attitudes than people who did not try to counterargue if they make a simple inference that "the position must be bad if I tried to counterargue." Or, people who fail to counterargue might have more favorable attitudes than people who did not try to counterargue if they make the inference that "the position must be very favorable indeed if I could not generate counterarguments." However, if these attitude effects were to occur it would complicate interpretation of attitude strength effects, because attitudes of different extremity would be compared. Fortunately, our pilot testing of topics and messages enabled us to hold the amount of attitude change constant across the directed-negative thinking and undirected thinking groups so that certainty effects could be examined unconfounded by extremity.
} 
considered the thoughts that generally came to mind (i.e., mostly positive thoughts in the case of a message containing only very strong arguments), may realize merely that the proposal has advantages and fail to realize that there are few drawbacks. Thus, whereas both groups might think, "Wow, I had many positive thoughts to this message," only individuals who had tried but failed to generate negative thoughts would likely have access to the extra metacognition that "I really have no negative thoughts about this message!" We hypothesize that one consequence of the recognition that the advocacy has many positive features and possesses few drawbacks should be enhanced certainty in one's message-congruent attitude compared with a focus on the positive features alone.

\section{Overview of the Present Research}

In the present research, we tested whether attitudes resulting from failed counterarguing differ in the certainty with which they are held compared with the same attitudes resulting from undirected thinking. Specifically, we directed participants to focus on either their general thoughts or their negative thoughts to a message containing very strong arguments. Because we used very strong arguments, counterarguing was expected to fail to inhibit attitude change relative to a group that did not attempt to counterargue. Our primary hypothesis was that although failed counterarguing would lead to attitudes that were equivalent in valence to those that followed undirected thinking, the former attitudes would be held with greater certainty. This hypothesis was tested in multiple experiments using a range of attitude objects.

Furthermore, because one consequence of attitude certainty is that it has been shown to moderate the attitude-behavior and attitude-intention relationships (Fazio \& Zanna, 1978; Tormala \& Petty, 2002), we examined this consequence in Experiments 1-4. To the extent that this occurs, it suggests that the certainty we have produced is consequential. Finally, in Experiment 5, we tested whether the underlying mechanism for the proposed certainty effects is participants' thoughts about the negative thoughts they possess (i.e., metacognitions about their own negative thoughts).

\section{Experiment 1}

In our first experiment, the attitude object consisted of a novel aspirin product. Because we were interested in differences in attitude certainty that follow failed counterarguing versus undirected thinking, we developed materials that would lead to comparable amounts of attitude change in the two groups. If the groups differed in the valence or extremity of their attitudes, this would complicate interpretation of the certainty results, as more extreme attitudes are typically stronger on a variety of dimensions (see Petty \& Krosnick, 1995). Therefore, our messages included very compelling arguments that elicited relatively few negative thoughts, even when participants were asked to generate them. In addition to the undirected and directed-negative (i.e., counterarguing) conditions, we also included a condition in which participants were asked to generate positive thoughts (directed-positive). The inclusion of a directed-positive condition allows us to rule out the possibility that directed thinking in general may lead to more certainty. If directed thinking in general does not increase certainty, but there is something unique about failing to counterargue a strong message, then we should only observe enhanced certainty in the directed-negative condition. We also measured behavioral intentions to examine whether the expected enhanced certainty affected the correspondence between attitudes and intentions.

\section{Method}

\section{Participants}

Seventy-seven Ohio State University undergraduates served as participants in exchange for partial fulfillment of a requirement in their introductory psychology course. Participants were randomly assigned to one of four conditions (control, undirected thinking, directed-positive thinking, directed-negative thinking).

\section{Procedure}

On entering the lab, the students were told that they would be participating in a study on consumer research. Specifically, participants were informed that they would provide their attitudes and opinions on a product that was selected at random by the computer. In actuality, all participants received an advertisement for the same fictitious brand of aspirin, "Relieve."

Participants in the control condition provided their attitudes in the absence of any information about Relieve other than it was a brand of aspirin. Participants in the three experimental conditions were given a thinking instruction and were then exposed to an advertisement for the product. Participants were told to either focus on their thoughts (undirected thinking), positive thoughts (directed-positive thinking), or negative thoughts (directed-negative thinking). Participants were told they should type "NONE" if they did not have thoughts. This was intended to serve as a subtle reminder of failure to generate thoughts in the undirected thinking condition, or positive/negative thoughts in the respective directed thinking conditions.

After the thought instructions, all experimental groups read an advertisement that contained three cogent arguments designed to be difficult to counterargue. Specifically, in a pilot study,19 participants were presented with each of the three arguments and asked to list a negative thought or to type "NONE" if they could not produce one. Across all participants, only $26 \%$ of thoughts generated were negative. The remaining $74 \%$ were reported as "NONE," indicating that participants did not have any natural negative thoughts. Thus, the arguments were shown to be difficult to counterargue (see Appendix for arguments).

After participants read the advertisement, each of the three arguments in favor of the product was repeated, one at a time, on the computer screen. Participants were instructed, depending on condition, to provide a thought, positive thought, or negative thought. Participants were also informed that, in the event they had none of the requested type of thought, to type "NONE." Following the thought listing, participants' attitudes, attitude certainty, and behavioral intentions were assessed. Participants were then thanked and debriefed.

\section{Independent Variable}

Participants in the experimental groups were directed to focus on thoughts, positive thoughts, or negative thoughts. Participants in the control condition did not receive an advertisement or a thought-listing task, as these participants simply served to establish premessage attitudes. The instructions for participants in the undirected condition were as follows:

You will be given information about a new aspirin that may be test marketed in Columbus in the upcoming year.

A common method of gauging consumers' response to products is to assess what THOUGHTS people have about using the products. 
Therefore, you will be asked to focus on and list the THOUGHTS you have about using the aspirin you read about.

Of course, you might not have any THOUGHTS about using the aspirin you read about. If you do not have any THOUGHTS about the aspirin you read about, we would like you to type the word NONE in capital letters.

In the directed-positive condition the word positive was added before each instance of the word thoughts, whereas in the directed-negative condition the word negative was added before each instance of the word thoughts.

\section{Dependent Variables}

Thoughts. Two judges, blind to the conditions from which the thoughts came, coded the thoughts as positive, negative, neutral, or absent (i.e., a "NONE" response). Interrater agreement across all studies was above $90 \%$, and disagreements were resolved through discussion. In all studies, we report the average percentage of each type of thought generated across participants. That is, we computed the percentage of each type of thought by first calculating a percentage for each participant and then taking an average across participants.

Attitude. Attitudes toward Relieve were assessed with four 9-point semantic differential scales (good-bad, favorable-unfavorable, positivenegative, and support-oppose). All scales ranged from 1 to 9 , with negative descriptors anchored at 1 and positive descriptors anchored at 9. The four scales were collapsed to form an aggregate measure of attitudes $(\alpha=$ .97).

Attitude certainty. Attitude certainty was assessed with a composite of two items $(\alpha=.93)$. Participants were asked, "How certain are you of your feelings toward Relieve?" and "How convinced are you of your attitude toward Relieve?" Both items were completed on 9-point scales, with $1=$ not at all and $9=$ extremely.

Behavioral intentions. We informed participants that Columbus was often used as a test market for products and that Relieve would be available for trial use in the upcoming months. Participants were asked how likely they would be to purchase Relieve, try a free sample, and/or purchase Relieve at a sale price, once it became available in Columbus $(\alpha=.74)$. All questions were answered on 9-point scales, with $1=$ not at all likely and $9=$ extremely likely. Behavioral intentions have long been accepted as the best single predictor of actual behavior (Fishbein \& Ajzen, 1975, 1981).

\section{Results}

\section{Thoughts}

Participants in the undirected thinking condition listed very few negative thoughts (6.7\%), some neutral thoughts (10\%), and some "NONE" responses $(23.3 \%)$ but had primarily positive thoughts (60\%). Participants instructed to generate positive thoughts generated no negative thoughts $(0 \%)$, gave some neutral thoughts (3.5\%) and "NONE" responses (24.6\%), and also listed primarily positive thoughts (71.9\%). Participants instructed to generate negative thoughts tended to generate more negative thoughts (18.5\%) on average than those instructed to generate thoughts, $t(36)=$ $1.97, p=.06$, or positive thoughts, $t(35)=3.00, p<.005$. However, individuals instructed to generate negative thoughts primarily gave "NONE" responses $(75.9 \%)$, with no positive thoughts (0\%) and some neutral thoughts (5.6\%).

\section{Attitudes}

There was a significant effect of condition on attitudes, $F(3$, $73)=18.78, p<.01$. Relative to the control group $(M=5.09$,
$S D=1.38$ ), participants who received the advertisement for the product had more favorable attitudes toward the product, whether their thinking was undirected $(M=7.68, S D=1.16), t(38)=$ $6.42, p<.01$; directed toward generating negative thoughts $(M=$ 7.67, $S D=1.14), t(36)=6.25, p<.01$; or directed toward generating positive thoughts $(M=7.28, S D=1.37), t(37)=4.97$, $p<.01$. An omnibus analysis of variance revealed that attitudes in the treatment conditions did not differ from one another, $F(2$, 54) $=.65, p=.53$.

\section{Attitude Certainty}

There was a significant effect of treatment on attitude certainty, $F(2,54)=4.51, p=.02$. Individuals instructed to generate negative thoughts $(M=7.64, S D=1.20)$ were more certain of their attitudes than individuals who attempted to generate either thoughts $(M=6.72, S D=1.20), t(36)=2.35, p=.02$, or positive thoughts $(M=6.50, S D=1.26), t(35)=2.82, p<.01$. Individuals instructed to generate thoughts and positive thoughts showed equivalent certainty, $t(37)=0.57, p=.57 .^{3}$

\section{Behavioral Intentions}

There were no differences in behavioral intentions between the undirected $(M=7.28, S D=1.31)$, directed-positive $(M=6.23$, $S D=2.23)$, and directed-negative $(M=7.20, S D=1.58)$ groups, $F(2,54)=2.17, p=.12$. However, congruent with our hypothesis, the new attitudes of participants were more predictive of behavioral intentions in the directed-negative condition $(r=.80)$ than in the undirected $(r=.39, z=1.94, p<.05$, one-tailed) or directedpositive condition $(r=.31, z=2.16, p<.05$, one-tailed $){ }^{4}$ Correlations in the latter two groups did not differ $(z=.26, p=$ .40 , one-tailed).

\section{Discussion}

Experiment 1 examined the impact of directed-negative thinking versus undirected and directed-positive thinking. The attempted counterarguing failed in the directed-negative condition, as these individuals were more favorable toward the advocacy than individuals who were not exposed to the message, and they showed favorable attitudes that were equivalent to those who were exposed to the message but were not directed to counterargue. Thus, on the basis of the attitude measure alone, it would appear that new attitudes formed as a result of directed-negative, directed-positive, or undirected thinking were functionally equivalent. However,

\footnotetext{
${ }^{3}$ The control group is not included in the attitude certainty analyses because the experimental and control groups had attitudes differing in extremity. This analysis is focused on attitude certainty of similar attitudes, and therefore certainty in the control group $(M=4.33, S D=2.36)$ is not pertinent. Nevertheless, it is not surprising that individuals who received information about the product were more certain of their attitudes toward that product than those who were unfamiliar with the product (i.e., control participants).

${ }^{4}$ All attitude-behavior tests were conducted using one-tailed tests because stronger attitudes are universally theorized to be more predictive of behavior and behavioral intentions (for a review, see Krosnick \& Petty, 1995). That is, one-tailed tests were theoretically driven and increased power in each individual study.
} 
inspection of the certainty with which people held these equivalent attitudes yielded significant differences. Individuals were more confident of their attitudes when they had been directed to find fault in the message than when they were directed to find merit or were undirected in their thinking. The inclusion of the directedpositive conditions also suggests that it is not directed thinking per se that enhances attitude certainty, but rather that it was specifically focusing on finding fault in the message (and finding none) that increased certainty in one's new attitude.

Furthermore, the differences in attitude certainty were consequential. Specifically, the difference in certainty manifested itself in differences in the predictive utility of the new attitudes. That is, more confidently held attitudes were more predictive of behavioral intentions, consistent with prior work on attitude certainty (Fazio $\&$ Zanna, 1978). These results give initial support to the idea that although failed counterarguing can lead to attitudes that are equivalent on the surface, failed counterarguing can have effects on the strength properties of the new attitudes.

\section{Experiment 2}

Experiment 2 was designed to explore a possible explanation for our results based on reactance theory. Reactance theory (Brehm, 1966, 1972) suggests that when an individual feels his or her personal freedom is threatened, he or she acts in a manner to restore that freedom. In the present research, telling participants to list negative thoughts and nothing else is essentially limiting their freedom by providing them with a narrow set of options. To the extent that participants felt that their personal freedom was compromised by the directed-thought technique, participants may have been placed in a state of reactance. As a consequence of invoked reactance, individuals might actually adopt the goal of accepting the message. Although no research has tested the impact of reactance on attitude certainty, it is possible that expressing more conviction about one's attitude is one means of saying "you want me to reject the message, but instead I will be extra confident that the position you want me to reject is right!" If so, reactance might have accounted for the results of our initial study. Although participants in the directed-positive condition also had their options narrowed, if requesting favorability produced reactance, it would presumably have made people want to reject the message or express less certainty in the position advocated. Thus, reactance provides a viable alternative for the effects we observed only in the directed-negative thoughts condition.

On the other hand, reactance might not have been invoked in our directed-negative thinking participants because although we requested negative thoughts, we allowed the option of listing "NONE" if no negative thoughts could be generated. We can test the viability of the reactance explanation by requiring participants to list negative thoughts without providing the explicit option of listing "NONE." By requiring participants to list negative thoughts and not giving them the option to write "NONE," we would clearly be encroaching on their personal freedom. If reactance is responsible for the increased certainty we observed in the failed counterarguing conditions, then it should be equally prominent, if not more pronounced, when people are required to list counterarguments. However, if requiring participants to list negative thoughts leads to less attitude change and less certainty, the reactance hypothesis can be dismissed. Thus, in Experiment 2, in addition to the directed-negative manipulation used in Experiment 1, we included a condition in which participants were required to generate counterarguments.

\section{Method}

\section{Participants}

One hundred four Ohio State University undergraduates served as participants in return for partial fulfillment of a requirement in an introductory psychology course. Participants were randomly assigned to one of four conditions (control, undirected thinking, directed-negative thinking, required-negative thinking)

\section{Procedure}

The procedure was identical to that of Experiment 1, with two exceptions. First, having demonstrated that it is not directed thinking per se that increases certainty, we did not include a directed-positive condition. Second, an additional condition was added in which participants were required to list negative thoughts. This condition was identical to the directednegative condition except participants were not told that they could type "NONE" if they had no negative thoughts. In addition to not giving participants an option to fail, the computer program was set so that there was no way participants could advance the screen without typing a response. As in the previous experiments, participants were asked to report their attitudes $(\alpha=.96)$, attitude certainty $(\alpha=.86)$, and behavioral intentions $(\alpha=.75)$.

\section{Results}

\section{Thoughts}

Participants simply instructed to generate thoughts again had relatively few negative thoughts $(12.8 \%)$ and primarily positive thoughts $(53.9 \%)$, but they also gave some neutral $(5.1 \%)$ and "NONE" $(28.2 \%)$ responses. Participants instructed to generate negative thoughts but allowed to list "NONE" tended to generate slightly more negative thoughts (19\%) than individuals in the thought condition, though this difference was not significant $t(50)=0.79, p=.43$. Individuals allowed to type "NONE" mostly gave "NONE" responses (81\%). However, when participants were required to list negative thoughts, they complied (83.3\%), with only a few thoughts being neutral $(16.7 \%)$. Many of the negative thoughts in this condition consisted of resistance strategies associated with source derogation ("Did the aspirin company pay the AMA for this rating?"), skepticism ("Does it really work in minutes?"), and attitude bolstering ("Maybe other aspirins are better for other things."). Thus, when truly forced to attack the message, participants began to implement strategies beyond pure counterarguing, presumably because the arguments were developed to minimize individuals' ability to argue against them.

\section{Attitudes}

There was a significant effect of condition on attitudes, $F(3$, $100)=17.86, p<.001$. Compared with the control group $(M=$ $5.29, S D=1.16$ ), participants who received the advertisement for the product had more favorable attitudes toward the product whether they attempted to generate thoughts $(M=7.13, S D=$ 1.47), $t(50)=5.01, p<.01$, attempted to generate negative thoughts $(M=7.82, S D=1.48), t(50)=6.84, p<.01$, or were 
required to generate negative thoughts $(M=6.24, S D=1.14)$, $t(50)=2.96, p<.01$. However, the attitudes of participants required to generate negative thoughts differed significantly from the attitudes of those instructed to generate thoughts, $t(50)=2.45$, $p=.02$, or negative thoughts, $t(50)=4.31, p<.01$, but the latter two groups did not differ from one another, $t(50)=1.67, p=.10$.

\section{Attitude Certainty}

As in Experiment 1, our interest in attitude certainty focuses on the two conditions in which attitudes were equivalent and most favorable toward the advocacy, namely when participants were undirected in their thinking or directed to generate negative thoughts but given a chance to fail. There was a significant effect of treatment on attitude certainty, $t(50)=3.35, p<.01$. Replicating the findings of Experiment 1, participants who attempted to generate negative thoughts $(M=7.33, S D=.85)$ were more certain of their attitudes than individuals who simply attempted to generate thoughts $(M=6.17, S D=1.54){ }^{5}$

\section{Behavioral Intentions}

As in Experiment 1, there was no difference in mean behavioral intentions of participants in the undirected $(M=6.81, S D=2.21)$ and directed-negative $(M=7.45, S D=1.69)$ conditions, $t(50)=$ $1.18, p=.25$. However, participants tended to show stronger attitude-behavioral intention correlations when they had failed to generate negative thoughts $(r=.74)$ than when they attempted to generate thoughts $(r=.46 ; z=1.53 ; p=.06$, one-tailed).

\section{Discussion}

Experiment 2 replicates and extends the findings of our previous study. As in Experiment 1, directing people to focus on their negative thoughts toward a message resulted in attitude change equivalent to that seen in participants directed to simply think about the message. A different pattern was obtained when people were required to list negative thoughts. Although these individuals still showed more favorability toward the advocacy than people who did not receive a message, they were significantly less favorable than the other treatment groups. Furthermore, they had more negative thoughts than individuals given the option to fail.

Although the forced negative thoughts group was generally successful in accomplishing the task (i.e., they generated the requested negative thoughts), they still changed their attitudes, though not to the same extent as individuals who had the option of failing to counterargue. Of greatest interest, the pattern of results obtained renders the reactance interpretation of our certainty findings unlikely. That is, when participants were required to list negative thoughts and not given an explicit option to fail, they listed significantly more negative thoughts. If requiring negative thoughts induces reactance, this group should have shown the most favorable attitudes and/or the most certainty, but it did not.

Replicating the findings of the first two experiments, when attitudes were formed as a result of a failed directed-negative thinking attempt, participants exhibited more certainty in their new attitudes. As in Experiment 1, this certainty had implications for the attitude-behavior relationship. Thus, our initial experiments demonstrate that attempted counterarguing that is unsuccessful can produce new attitudes that are stronger than the same new attitudes that stem from undirected thinking about the identical message.

\section{Experiment 3}

Although the previous studies clearly demonstrate that directednegative thinking produced stronger attitudes relative to undirected thinking, the generalizability of this finding remains unclear. Perhaps most important, the previous experiments used a single topic, toward which participants were generally neutral. It remains to be seen whether the same effect would hold for a counterattitudinal topic toward which attitudes are initially negative. It could be, for instance, that a counterattitudinal topic would invariably lead to less agreement when individuals are instructed to generate negative thoughts, as in the required thought condition in Experiment 2. In addition, the aspirin topic we used is not one of particular relevance or importance to our participants. Thus, we wanted to see whether the effects would hold for issues that people felt were personally relevant and involving (Petty \& Cacioppo, 1979).

To address these issues, Experiment 3 used a counterattitudinal attitude topic (implementation of senior comprehensive exams), to examine whether our findings generalize to a new topic and one counterattitudinal in nature. Personal relevance of the issue was also varied to examine whether the effects are confined to issues of low relevance or importance.

In Experiment 3 we also assessed elaboration, or amount of thinking. Past research has demonstrated that higher elaboration is associated with stronger attitudes (see Petty, Haugtvedt, \& Smith, 1995). Thus, it could be that directed-negative thinking may entail more effort in general. To test this possibility, we included measures to assess the amount of thinking participants reported doing in the various conditions.

Finally, there are also some methodological questions about the generalizability of the effect. Specifically, in the previous studies, participants were specifically asked to type the word none if they did not have negative thoughts. Although we do not believe this is key to obtaining our effect, it is possible that explicitly having participants type "NONE" makes the fact that they do not have negative thoughts more salient than it naturally would be. Although the effect would still be of conceptual interest if this were the case, the effect would be less likely to occur in the real world if this methodological detail were required for the effect to emerge. We addressed this issue by allowing and telling participants they could skip the thought listing if they did not have a negative thought to type. Thus, we still made it clear that they did not have to type a negative thought, to avoid making the task forced, but we no longer asked them explicitly to type the word none. This change was implemented in all of the remaining experiments.

\footnotetext{
${ }^{5}$ We did not compare the negative forced group with either of these groups because this group did not exhibit equivalent attitudes (i.e., they were significantly less favorable to the advocacy). Thus, their certainty refers to a different attitude. Nevertheless, these individuals were not very confident of their new attitude $(M=5.33, S D=1.56)$. This likely stemmed from their lack of confidence in the counterarguments that they were required to generate (Petty et al., 2002). In fact, these individuals were no more certain than individuals who received no message $(M=$ $5.00, S D=2.13$ )
} 


\section{Method}

\section{Participants}

One hundred six Ohio State University undergraduates served as participants in return for partial fulfillment of a requirement in an introductory psychology course. Participants were assigned randomly to the conditions of a 2 (issue relevance: low, high) $\times 3$ (instruction set: control, undirected thinking, directed-negative thinking) between-subjects factorial design.

\section{Procedure}

Participants were informed that they would provide their attitudes and opinions on a campus issue. All participants then received information about a proposal to implement senior comprehensive exams at the Ohio State University. In essence, participants were told that a policy of senior comprehensive exams would require seniors to take and pass an exam in their major area before they could graduate. After receiving the information about the exams, participants in the experimental groups were told they would be receiving the message arguments and were instructed to focus on either their thoughts or their negative thoughts, and then were given a very strong message in favor of instituting the exams (see Appendix). Participants in the control group received no additional information about the exams. All participants then completed measures to assess their attitudes, attitude certainty, and behavioral intentions. We also included items to measure elaboration and the perceived relevance of the issue.

\section{Independent Variables}

Relevance. In the low-relevance conditions, participants were told that the senior comprehensive exam policy was proposed to be implemented in 10 years. In the high-relevance conditions, participants were told that the senior comprehensive exam policy was proposed to be implemented in 2 years. This manipulation has been used in numerous prior studies (e.g., Petty \& Cacioppo, 1979; for a review, see Petty, Cacioppo, \& Haugtvedt, 1992).

Instruction set. Participants were told to focus on and list either thoughts or negative thoughts toward the senior comprehensive exam policy. However, rather than having participants explicitly type "NONE" if they had no thoughts as in previous studies, participants were simply told they could skip the thought listing if they did not have the requested thoughts.

\section{Dependent Variables}

Thoughts. As in the previous studies, thoughts were coded as positive, negative, neutral, or absent with respect to the advocated position.

Attitude. Attitudes toward senior comprehensive exams consisted of an aggregate measure that used the same attitude items as in the previous experiments $(\alpha=.98)$.

Attitude certainty. Attitude certainty was assessed by asking participants, "How certain are you of your attitude toward senior comprehensive exams?"6 and "How convinced are you of your attitude toward senior comprehensive exams?" Both items were completed on 9-point scales, with $1=$ not at all and $9=$ extremely, and combined to form a single index $(\alpha=.73)$.

Behavioral intentions. Participants were informed that the senior comprehensive exam policy would soon be put to a vote and were asked how they would vote and how they would tell their friends to vote. Both questions were answered on 9-point scales where $1=$ "Definitely vote against" and $9=$ "Definitely vote in favor." and were aggregated to form a single index $(\alpha=.97)$.

Elaboration. To assess elaboration, participants were asked how much they thought about the message, how much attention they gave to the message, and how deeply they thought about the message. These items and variants of these items have been found to be sensitive to elaboration in past research (e.g., Tormala, Petty, \& Briñol, 2002). Each item was assessed on a 9-point scale and the items were aggregated to form a composite measure $(\alpha=.86)$.

Relevance. Relevance was assessed by asking participants, "How personally involved did you feel with the topic you read about?" Participants responded on a 9-point scale anchored at $1=$ not at all, $9=$ very much .

\section{Results}

\section{Relevance}

There was a main effect of the relevance manipulation such that participants reported the exams as more relevant to them in the high-relevance condition $(M=7.27, S D=2.17)$ compared with the low-relevance condition $(M=5.29, S D=2.41), t(104)=$ $4.39, p<.01$.

\section{Elaboration}

There were no main effects or interactions for elaboration (all $p$ s $>$.26). In fact, individuals reported high levels of elaboration regardless of whether they were in the low-relevance $(M=7.21$, $S D=1.54)$ or high-relevance $(M=7.02, S D=1.46)$ condition Likewise, individuals reported relatively high levels of elaboration regardless of whether they were undirected in their thinking $(M=$ $6.94, S D=1.68)$ or directed to generate negative thoughts $(M=$ $7.30, S D=1.30)$. In prior work where a manipulation of relevance affected the extent of elaboration (e.g., Petty \& Cacioppo, 1979), no instructions were given to participants about generating thoughts. In contrast, in the current research, it was desirable for all participants to engage in the same level of elaboration and to vary perceived personal relevance independent of the extent of thinking. Instructing the participants to generate thoughts (or negative thoughts) accomplished this comparable level of thinking across all groups.

\section{Thoughts}

Table 1 shows the average of participants' thoughts as a function of condition. As in the previous studies, participants' predominant thoughts were positive in the undirected thinking conditions, whereas participants' dominant response was a nonresponse in the directed negative conditions. Overall, participants had more negative thoughts when the message was of high versus low relevance, $t(66)=3.73, p<.01$. However, within each level of relevance, the number of negative thoughts did not significantly differ from one another as a function of the thought instruction set $(p s>.28)$.

\section{Attitudes}

There was a main effect of relevance on attitudes such that individuals were more negative toward the comprehensive exam proposal when it was high in relevance $(M=4.31, S D=2.16)$ compared with when it was of low relevance $(M=5.69, S D=$ $2.10), F(1,100)=8.36, p<.01$. There was also a significant main

\footnotetext{
${ }^{6}$ In the prior studies, this measure had asked how certain participants were of their feelings toward the attitude object, but we replaced feelings with attitude to more directly tap the variable of interest.
} 
Table 1

Percentage of Thoughts and Means (SDs) for Attitudes, Certainty, and Behavioral Intentions as a Function of Relevance and Instructional Set in Experiment 3

\begin{tabular}{|c|c|c|c|c|c|c|c|}
\hline \multirow[b]{2}{*}{ Relevance and instructional set } & \multicolumn{4}{|c|}{ Thoughts (\%) } & \multicolumn{3}{|c|}{ Rating scales } \\
\hline & Neutral & Positive & Negative & None & Attitudes & Certainty & Intentions \\
\hline \multicolumn{8}{|l|}{ Low relevance } \\
\hline Undirected $(n=19)$ & 10.5 & 63.2 & 7.9 & 18.4 & $6.30(1.75)$ & $6.47(1.65)$ & $5.97(2.04)$ \\
\hline Directed-negative $(n=20)$ & 2.5 & 0.0 & 15.0 & 82.5 & $6.48(2.54)$ & $7.38(1.11)$ & $5.95(2.79)$ \\
\hline \multicolumn{8}{|l|}{ High relevance } \\
\hline Undirected $(n=14)$ & 0.0 & 46.4 & 25.0 & 28.6 & $5.02(1.79)$ & $5.79(1.24)$ & $5.00(1.61)$ \\
\hline Directed-negative $(n=15)$ & 6.7 & 0.0 & 40.0 & 53.3 & $5.07(2.63)$ & $7.17(1.48)$ & $4.20(2.60)$ \\
\hline
\end{tabular}

effect of instruction set, $F(2,100)=9.93, p<.01$, such that relative to the control groups $(M=3.72, S D=2.23)$ individuals who received a message had more favorable attitudes, whether they attempted to generate thoughts $(M=5.76, S D=1.85)$, or negative thoughts $(M=5.87, S D=2.64)$. Means for specific cells are displayed in Table 1. There was no interaction between relevance and instruction set, $F(2,100)=0.06, p=.95$. Thus, although individuals in the high-relevance conditions were more opposed to the exams overall, the effect of attempted counterarguing was similar in high- and low-relevance conditions in that the attempted counterarguing group showed the same extent of favorability toward the issue (relative to the control condition) as the instructed thought group.

\section{Attitude Certainty}

As in our prior experiments, our interest in attitude certainty focuses on the conditions in which attitudes were equivalently favorable toward the issue, namely, when participants attempted to generate thoughts or attempted to generate negative thoughts in response to a message. There was a single main effect such that individuals were more certain of their attitudes when they had been directed to consider their negative thoughts toward the message $(M=7.29, S D=1.27)$ than when they were undirected in their thinking $(M=6.18, S D=1.51), F(1,64)=11.23, p=.01$. There was no main effect for relevance, $F(1,64)=1.73, p=.19$, nor was there any interaction between instruction set and relevance, $F(1,64)=0.50, p=.48$, indicating that the difference in certainty was unaffected by level of personal relevance. ${ }^{7}$

\section{Behavioral Intentions}

There was a main effect only on behavioral intentions such that individuals had more positive intentions in the low-relevance condition than in the high-relevance condition, $F(1,64)=5.61$, $p=.02$. More importantly, as in previous experiments, participants showed stronger attitude-intention correlations when they tried but failed to generate negative thoughts $(r=.87)$ than when they attempted to generate thoughts $(r=.72 ; z=1.66 ; p<.05$, one-tailed).

\section{Discussion}

Experiment 3 makes multiple contributions to the understanding of failed counterarguing compared with undirected thinking. First, we replicated our basic findings for a new message topic, senior comprehensive exams, that was counterattitudinal to participants, especially in the high relevance version. Thus, our results can be generalized beyond neutral topics, beyond uninvolving topics, and beyond the consumer domain.

Increasing personal relevance influenced the number of negative thoughts generated, and individuals in the high-relevance condition were less favorable toward the proposal than were individuals in the low-relevance conditions. However, it was still the case that less than half of their thoughts regarding the message were negative, and the message was still strong enough to produce more favorable attitudes than the no-message control. Furthermore, attitudes were held with greater certainty when participants had been explicitly instructed to generate negative thoughts than when they processed the same high-relevance message and showed the same amount of attitude change under mere thought instructions. Thus, our results suggest that relevance per se does not moderate the effect, at least in a situation in which the message arguments are very strong and the message is not so counterattitudinal or important that people will use any means (e.g., source derogation, emotional reactions) to reject it (e.g., Zuwerink \& Devine, 1996). Furthermore, elaboration did not differ as a function of condition, suggesting that the enhanced certainty effects are not the result of differential elaboration

This study also ruled out the possibility that our effects require participants be given the option of recording "NONE" when they had no negative thoughts. To examine this, we modified the procedure so that participants only had to skip listing a thought and the earlier results were replicated. Thus, this methodological procedure is not responsible for our effects.

Experiments 1-3 demonstrate not only that counterarguing can lead to enhanced certainty relative to undirected thinking, but also that this increased certainty has implications for predicting behavioral intentions. Furthermore, there is evidence that the observed increase in the attitude-behavioral intention correlations as a function of our manipulation is due, at least in part, to the differences

\footnotetext{
${ }^{7}$ The certainty effect held for each relevance condition even when the data were not collapsed. When relevance was high, individuals were more certain in the directed-negative condition $(M=7.17, S D=1.48)$ compared with the undirected condition $(M=5.79, S D=1.24), t(27)=2.71, p=$ .01. Likewise, when relevance was low, individuals were more certain in the directed-negative condition $(M=7.38 S D=1.11)$ compared with the undirected condition $(M=6.47, S D=1.65), t(37)=2.01, p=.05$.
} 
in certainty. Specifically, collapsing across Experiments 1-3 for maximum power, there was a direct effect of our manipulation on certainty. Despite the fact that, across all three studies, individuals instructed to generate negative thoughts had attitudes comparable to those instructed to generate thoughts, $t(156)=0.71, p=.48$, individuals instructed to generate negative thoughts were more certain of their attitudes $(M=7.38, S D=1.12)$ than were individuals instructed to generate thoughts $(M=6.32, S D=1.45)$, $t(156)=5.15, p<.01$. Furthermore, the average attitudebehavioral intention correlation was greater in the directed negative thought condition $(r=.87, p<.01)$ than in the undirected thinking condition $(r=.65, p<.01 ; z=3.42, p<.01$, one-tailed).

To examine whether the enhanced certainty contributed to the observed increases in attitude-behavior consistency, we conducted a series of regression analyses. In the first regression analysis, we examined the joint impact of attitudes and our manipulation in predicting behavioral intentions. To examine this, we dummy coded our instruction manipulation as 0 (instructed to generate thoughts) or 1 (instructed to generate negative thoughts). Attitudes and the instruction manipulation were entered in the first step of the regression analyses, and the interaction term was entered in the second step. Replicating the simple correlation analysis reported earlier, both attitudes $(\beta=.78, p<.01)$ and the Attitude $\times$ Instruction Set interaction $(\beta=.39, p=.04)$ predicted behavioral intentions. Specifically, attitudes were more predictive of behavioral intentions when individuals had been instructed to generate negative thoughts versus thoughts.

Next, we examined whether attitude certainty moderated the attitude-behavioral intention relationship (as found by Fazio \& Zanna, 1978). To examine this, we entered attitudes and certainty in the first step of a hierarchical regression, and entered their interaction in the second step. The results of this analysis revealed that both attitudes $(\beta=0.78, p<.01)$ and the Attitude $\times$ Certainty interaction $(\beta=1.01, p<.01)$ predicted behavioral intentions. Specifically, attitudes became more predictive of behavioral intentions as certainty increased. Finally, in the third step of the hierarchical regression analysis we entered the Attitude $\times$ Instruction Set interaction and found that it no longer explained any additional variance $(\beta=.23, p=.28)$. In essence, once the Attitude $\times$ Certainty interaction was controlled for, the Attitude $\times$ Message Instruction interaction became nonsignificant, suggesting that the increased certainty contributed to the observed increase in attitude-behavioral intention correspondence in the directednegative condition.

\section{Experiment 4}

Although the results of the previous experiments provide evidence that the increased certainty stemming from failed counterarguing has consequences for predicting behavior, it also raises an interesting question. Would the observed increase in the attitudebehavioral intention correspondence occur if certainty was not measured? That is, it is possible that by measuring certainty we were alerting participants to the fact that they were more certain, and thus they felt inclined to act in accordance with their attitudes. If measuring certainty is necessary to produce more consequential attitudes, the effects may have reduced utility in the real world. On the other hand, if attitudes become stronger after failed counter- arguing (i.e., more predictive of intentions) even if certainty is not measured, it suggests that the strength consequences flow more naturally from failed counterarguing and thus have greater importance in natural situations. To address this issue, in Experiment 4 we examined the impact of thought instruction on the correspondence between attitudes and intentions without measuring certainty.

In the prior experiments, we used either a novel brand of aspirin — one about which people had to form an initial attitude, or a relatively unfamiliar issue-the institution of senior comprehensive exams. It could be that the effects are confined to situations of attitude formation. Thus, it seemed important to examine these effects for an issue for which people held prior attitudes. To address this issue, Experiment 4 used a known consumer product, recognized by over $92 \%$ of participants in pilot testing: Cheer laundry detergent. The use of a well-known consumer product would demonstrate that the consequences of our effect hold even for a domain in which participants have some prior knowledge and a prior attitude. Furthermore, we used actual advertising content adapted from Cheer's products and Web site, ${ }^{8}$ which allowed us to convincingly demonstrate that individuals can encounter strong messages in real life that elicit few negative thoughts, even when they are told explicitly to try to generate them.

\section{Method}

\section{Participants}

One hundred twenty-three Ohio State University undergraduates served as participants in return for extra credit in an introductory marketing course. Participants were randomly assigned to control, undirected thinking, or directed-negative thinking conditions.

\section{Procedure}

Participants in the experimental conditions were given an advertisement for Cheer laundry detergent, based on arguments used on Cheer's Web site and advertising campaigns. Participants were instructed to list either thoughts or negative thoughts. As in Experiment 3, participants were told they could skip the item and did not have to type "NONE." Control participants were simply asked to provide their attitude toward Cheer without receiving any message. Finally, to examine whether the consequences of failed counterarguing on prediction of behavioral intentions were independent of assessing certainty, certainty was not measured in this study.

\section{Dependent Variables}

Thoughts. Thoughts were coded as positive, negative, neutral, or absent with respect to Cheer.

Attitude. Attitudes toward Cheer were assessed with the same attitude items used in the previous experiments $(\alpha=.98)$.

Behavioral intentions. To assess behavioral intentions, participants were asked "Will you use Cheer?" and "Will you purchase Cheer?" Both questions were answered on 9-point scales on which $1=$ definitely will not and $9=$ definitely will, and were aggregated to form a measure of behavioral intent $(\alpha=.98)$.

\footnotetext{
${ }^{8}$ Contact Derek D. Rucker for the arguments used in Experiments 4 and 5 .
} 


\section{Results}

\section{Thoughts}

On average, participants instructed to generate negative thoughts generated no positive thoughts $(0.0 \%)$, some negative thoughts $(13.5 \%)$, and a few neutral thoughts (4.0\%), but mostly gave no response $(82.5 \%)$. Participants in the uninstructed thinking condition had relatively few negative thoughts $(5.7 \%)$ and primarily positive thoughts (52\%), with some neutral (23.6\%) and some nonresponses $(18.7 \%)$. The amount of negative thoughts did not differ significantly as a function of condition, $t(81)=1.65, p=$ .10 .

\section{Attitudes}

There was a significant effect of condition on attitudes, $F(2$, $120)=9.29, p<.01$. Compared with the control group $(M=$ $5.86, S D=1.79$ ), participants who received the advertisement for the product had more favorable attitudes toward the product whether they were undirected in their thinking $(M=7.23, S D=$ $1.09), t(79)=4.15, p<.01$, or directed to generate negative thoughts $(M=7.07, S D=1.70), t(80)=3.13, p<.01$. As in prior studies, the attitudes of participants instructed to generate negative thoughts did not differ significantly from the attitudes of those instructed to generate thoughts, $t(81)=0.49, p=.63$.

\section{Behavioral Intentions}

Even though certainty was not measured, participants exhibited stronger attitude-behavioral intention correlations when they had attempted to generate negative thoughts $(r=.84)$ than when they attempted to generate thoughts $(r=.60 ; z=2.28 ; p=.01$, one-tailed). There was no difference in mean behavioral intentions of participants in the undirected $(M=6.61, S D=1.88)$ and directed-negative $(M=5.95, S D=2.27)$ conditions, $t(81)=1.45$, $p=.16$.

\section{Discussion}

Experiment 4 demonstrated that individuals whose attitudes changed (relative to a control group) after a failure to generate negative thoughts showed signs of attitude strength that were greater than individuals who changed to the same degree after undirected thinking. More specifically, these individuals showed greater attitude-behavioral intention consistency, even though certainty was neither mentioned nor measured. This study also suggests that enhanced attitude strength after the consideration of the faults in a message can occur for arguments that are found in the real world, and for attitude objects with which people have prior familiarity.

\section{Experiment 5}

Having clearly established that failing to counterargue can lead to more certain attitudes that are consequently more predictive of behavioral intentions, in Experiment 5 we focused on understanding the mechanism behind the enhanced attitude certainty effect. Although Experiment 1 ruled out directed thinking per se as a general contributor to attitude certainty (because directed positive thinking failed to enhance certainty), Experiment 2 ruled out reactance as a contributor (because required negative thinking failed to enhance certainty), and Experiment 3 demonstrated that self-reported elaboration is constant across thought instructions, it remains to be demonstrated what is responsible for the effects. That is, why does considering one's negative thoughts lead to greater attitude certainty than undirected thinking? We hypothesized earlier that the mechanism has to do with individuals' metacognitions about the number of negative thoughts they have regarding the topic, with participants perceiving themselves to have fewer negative thoughts when they actually attempted to generate negative thoughts than when they were undirected in their thinking. Other mechanisms may be possible, however.

One salient possibility derives from the subjective ease of generating various types of thoughts. For example, past research has shown that individuals hold their attitudes with greater certainty when they perceive it was easy to generate thoughts in favor of their attitudes and difficult to generate thoughts against their attitudes (e.g., Haddock, Rothman, Reber, \& Schwarz, 1998; Haddock, Rothman, \& Schwarz, 1996; Schwarz et al., 1991). In one relevant study, Haddock, Rothman, and Schwarz (1996) instructed participants to generate either three or seven favorable or unfavorable thoughts in response to a position they supported. When instructed to generate favorable thoughts, participants were more certain of their attitudes when asked to generate three versus seven favorable thoughts. However, when instructed to generate thoughts against their attitudes, participants were more certain of their attitudes when asked to generate seven versus three unfavorable thoughts. These findings can be explained by the perceived ease or difficulty associated with the task. On the one hand, generating three favorable thoughts is easier than generating seven, and this ease may translate into enhanced certainty in an individual's attitude (i.e., "It was easy to generate thoughts in favor of my attitude, so my attitude must be right!"). On the other hand, generating seven unfavorable thoughts is more difficult than generating three, and this difficulty can translate into greater certainty that an individual's initial attitude is correct (i.e., "It was difficult to generate thoughts against my attitude, so it must be right!"). These effects might further be explained by the fact that people would be more confident in their thoughts in favor of their attitudes when they were easy, rather than difficult, to generate, and less confident in their thoughts against their attitudes when they were difficult, rather than easy, to generate (Tormala et al., 2002).

Subjective ease might explain the results of the present research in the following manner. Individuals in the instructed negative thoughts condition might perceive that generating negative thoughts is more difficult than individuals who did not make a deliberate attempt to generate negative thoughts (i.e., individuals who were undirected in their thinking). Such individuals might reason that if it is so difficult to generate negative thoughts against the advocacy, then their thoughts against the advocacy must not be very good and/or the advocacy must be very good. Thus, they can be certain in their new attitudes that are consistent with the advocacy. Another alternative is that individuals who attempt to generate negative thoughts might actually infer that generating positive thoughts is easy. That is, even though they may not have put as much effort into generating positive thoughts, the experienced difficulty of generating negative thoughts could potentially lead them to infer that generating positive thoughts would be easy, 
and they might hold this view even more strongly than individuals who actually did generate positive thoughts (i.e., individuals undirected in their thinking). If they infer that generating positive thoughts to the advocacy is easy, they would have confidence in these positive thoughts and infer that the advocacy must be good. If so, their attitude in support of the advocacy must be good as well. To assess the ease possibility, we included measures of ease of positive and negative thought generation in our final experiment.

The other critical mediating mechanism tested in the following experiment is the one we suggested initially: that failing to counterargue a message would affect the metacognitions people have about their own negative thoughts about the message. It could be that it is not the ease or difficulty of counterarguing that is salient, but the perceived absence of negative thoughts that is critical to the effect. When people attempt to find fault in a message but realize the number of negative thoughts they could generate is very few or none, they are able to directly draw a firm conclusion about the negative aspects and counterpoints to the message. People are able to conclude, "I considered the faults in the message but could not generate any negative reactions. Thus, I really have no negative thoughts about this message." People who accept the message largely because of the presence of positive thoughts have not explicitly considered potential drawbacks. Thus, as mentioned earlier, only individuals who had considered their negative thoughts would be likely to make the inference that they truly have few negative thoughts about the message. This perception of a lack of negative thoughts, we hypothesize, helps crystallize conviction and certainty in the newly formed or changed attitude. According to this view, it is not individuals' subjective ease in generating negative thoughts that determines certainty, but rather it is individuals' perceptions of the extent to which negative thoughts are available. Alternatively, both subjective ease and individuals' perceptions of their own negativity may be partly responsible for the differences in certainty. To examine these possibilities, we assessed participants' own perceptions of how many negative thoughts they had about the attitude object. We also assessed participants' perception of the number of positive thoughts that they had about the attitude object, as this might contribute to the certainty effects as well (i.e., the absence of negative thoughts might lead people to infer they have many positive thoughts, and this perception might increase certainty).

\section{Method}

\section{Participants}

Participants were 133 Ohio State University undergraduates, who participated in exchange for partial fulfillment of a requirement in an introductory psychology course. Participants were randomly assigned to control, undirected thinking, and directed-negative thinking conditions.

\section{Procedure}

Participants were again exposed to the Cheer advertisement used in Experiment 4 . However, this time we included certainty measures as well as measures to assess the potential mediators of interest. The measures of behavioral intentions used in Experiment 4 were not included because we had already demonstrated the behavioral consequences in the prior studies and in this experiment turned to focus on the intervening variable (or variables) responsible for our certainty effect.

\section{Dependent Measures}

Attitudes. Attitudes were measured with the same items as in prior studies $(\alpha=.97)$

Certainty. Attitude certainty was assessed with the same items as in Experiment $3(\alpha=.89)$.

Subjective ease. To assess participants' subjective ease associated with generating negative thoughts and positive thoughts, we asked participants, "How difficult was it to generate negative thoughts in response to this message?" and, "How difficult was it to generate positive thoughts in response to this message?" These measures were adapted from those used with success in previous research on ease effects (see Haddock et al.,1998; Tormala et al., 2002).

Perceived number of thoughts. Participants' perceptions of how many negative thoughts they had were assessed by asking the following questions: "How many negative thoughts do you have toward Cheer?"; "What is the number of negative thoughts you have toward Cheer?"; and "How many negative thoughts could you generate toward Cheer?" $(\alpha=.86)$. Participants' perceived positive thoughts were assessed with the same three items, but the word negative was replaced with the word positive $(\alpha=.82)$. All scales consisted of 9 points and were anchored at $1=$ no negative [positive] thoughts and $9=$ many negative [positive] thoughts.

\section{Results}

\section{Actual Thoughts}

Participants generated a small number of negative thoughts when instructed to consider their negative thoughts $(M=8.1 \%)$, but the extent of negative thinking did not differ significantly from that shown by individuals instructed to simply list thoughts $(M=$ $3.4 \%), t(86)=1.17, p=.25$. Participants instructed to generate negative thoughts mostly gave no response $(91.1 \%)$, with a few neutral responses $(.8 \%)$. Individuals instructed to generate thoughts mostly generated positive thoughts $(48.1 \%)$, with some neutral thoughts $(6.2 \%)$ and many nonresponse options $(41.9 \%)$.

\section{Attitudes}

There was a significant effect of condition on attitudes, $F(2$, $130)=17.88, p<.01$. Compared with the control group $(M=$ $5.91, S D=1.73$ ), participants who received the advertisement for the product had more favorable attitudes toward the product than no-message controls, whether they were undirected in their thinking $(M=7.20, S D=1.24), t(86)=4.00, p<.01$, or directed to generate negative thoughts $(M=7.61, S D=1.17), t(88)=5.45$, $p<.01$. The attitudes of participants in the treatment conditions did not differ, $t(86)=1.58, p=.12$.

\section{Attitude Certainty}

Individuals directed to generate negative thoughts were more confident in their new attitudes $(M=7.56, S D=1.24)$ than individuals who were undirected in their thinking $(M=7.00$, $S D=1.43), t(86)=1.95, p=.05$.

\section{Mediation}

For successful mediation to be present, statistical analyses must first reveal a direct effect of the independent variable on the 
proposed mediator (Baron \& Kenny, 1986). Therefore, we first examined direct effects for each of our proposed mediators.

Subjective ease. There were no effects of thought instruction on how easy participants perceived it to be to generate negative thoughts $(\beta=.02, p=.86)$ or positive thoughts $(\beta=-.09, p=$ .43). However, consistent with past research on ease of retrieval effects (Haddock et al., 1996, 1998), we found that, collapsed across the thought instruction conditions, the more difficult participants reported the generation of negative thoughts to be, the more certain they were of their attitudes $(\beta=.24, p=.03)$. Likewise, the easier participants reported the generation of positive thoughts to be, the more certain they were of their attitudes $(\beta=$ $-.55, p<.001)$. These results suggest our measures of perceived ease appropriately assessed ease, as they replicated past research on the topic. However, these results also suggest that perceived ease was not a salient consequence of the type of processing manipulation (i.e., directed-negative vs. undirected thoughts) and could not contribute to the certainty effects that resulted from this manipulation.

Perceived number of thoughts. There was no effect of instruction set on individuals' perceptions of the number of positive thoughts they had $(\beta=.15, p=.17)$. There was, however, a significant effect of instruction set on individuals' perceptions of the number of negative thoughts they had $(\beta=-.25, p=.02)$. Individuals who were instructed to generate negative thoughts believed that they had fewer negative reactions to the product $(M=1.72, S D=.89)$ than individuals uninstructed in their thinking $(M=2.32, S D=1.39)$.

Having demonstrated that our manipulation influenced perceived negative thoughts, we followed the remainder of the criterion set forth by Baron and Kenny (1986) to establish mediation. Specifically, the proposed mediator should be correlated with the dependent variable after controlling for the independent variable, and the effect of the independent variable on the dependent should drop when the mediator is included in a simultaneous regression. As can be seen in Figure 1, this set of criteria is met. When perceived number of negative thoughts was included in the model, the relationship between the independent variable and the dependent variable was no longer significant $(\beta=.12, p=.25)$, but the relationship between perceived negative thoughts and certainty was $(\beta=-.33, p<.01)$. A formal test of mediation consisting of computing a 95\% confidence interval around the indirect effect (i.e., the path through the mediator) also revealed that the indirect effect was significantly different from zero $(95 \% \mathrm{CI}=.02-.57$; see Shrout \& Bolger, 2002).

Together, these analyses suggest the observed difference in certainty can be attributed to a difference in the perceived number of negative thoughts individuals believe they possess about the attitude object. Trying to generate negative thoughts and failing leads people to believe that they have fewer negative thoughts than people who are undirected in their thinking, and this in turn increases certainty in their new attitudes. The perception that there are few negative thoughts is less likely to occur to individuals who merely engage in thinking, and thus they are less confident in their new attitudes. What is important is the perception of individuals' negative thoughts rather than their actual negative thoughts. Participants' actual negative thoughts did not differ as a function of instruction set and therefore could not account for the differences in certainty.

\section{Discussion}

Although it seemed plausible that attempting to counterargue could be associated with greater subjective difficulty in generating counterarguments than merely thinking, this was not found to be the case. Thus, perceived difficulty was not a likely mediator of the attitude certainty effect we observed. This might have occurred because participants in the uninstructed thinking condition also assumed it would be difficult to counterargue, or individuals in the directed-negative thought condition were focused more on the absence of negative thoughts rather than on how difficult it was to generate them. In either case, subjective ease or difficulty was not responsible for the observed certainty effects. Furthermore, individuals' perceptions of the extent of their positive thoughts toward the product did not differ as a function of the instruction set. Thus, even though people in the directed-negative thoughts condition did not list as many positive thoughts as those in the undirected thinking condition, they perceived that they had as many positive thoughts. This suggests that failing to generate negative thoughts and actually generating positive thoughts both lead to similar conclusions about an individual's positive thoughts.

What did differ between participants in the experimental groups was their metacognitions about the number of negative thoughts available. Individuals who attempted to generate negative thoughts (but failed) perceived themselves to have fewer negative thoughts. It is important to note that it is this perception of one's negative thoughts rather than the actual number of negative thoughts listed, which did not differ, that mediated the relationship between thought instruction and attitude certainty. Thus, the metacognitions people have about their own negative thoughts appear to be responsible for the increased attitude certainty that follows the failure to counterargue a persuasive message. Just as the perceived presence of negativity is very diagnostic for people's evaluations

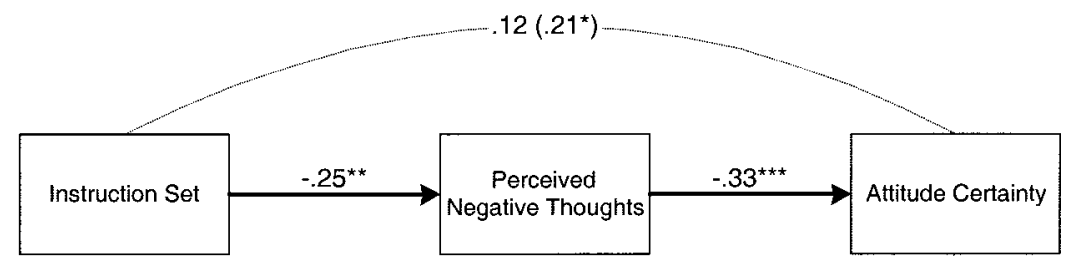

Figure 1. Mediational model of certainty effects in Experiment 5. Value in parentheses indicates the direct effect of instruction set on attitude certainty before the mediator was included in the model. * $p=.05$. ** $p<$ $.05 . * * * p<.01$. 
(Cacioppo \& Berntson, 1994; Peeters \& Czapinski, 1990), so too, apparently, is the perceived absence of negativity.

The fact that individuals' perceived positive thoughts did not differ as a function of instruction set also helps rule out an alternative interpretation of our mediator, namely that perceived negative thoughts is simply another index of certainty being influenced by the manipulation, and not the key intervening variable. Because individuals' perceptions of their positive thoughts did not differ as a function of the instruction set, this seems unlikely to be the case. If our measures of perceived thoughts were simply proxies for certainty, then both perceived positive and perceived negative thoughts should have differed as a function of instruction set. However, if these measures are sensitive to the unique metacognitive information about peoples' negative thoughts, as we have proposed, then only the perceived negative thoughts should have differed as a function of instruction set, as was found in the present study. Our measure of perceived negative thoughts is also not a proxy for actual negative thoughts, as the latter was not a mediator of the certainty effect. In addition, the correlation between perceived and actual negative thoughts was relatively small ( $r=.29, p<.01$ ), providing further evidence that perceptions of negative thoughts and actual negative thoughts are distinct constructs.

\section{General Discussion}

Across multiple experiments, we consistently found that when a persuader had very strong arguments to present, instructing people to try and find fault in a message led to attitudes equivalently favorable as those resulting from undirected thinking, but produced new attitudes that were held with more conviction and certainty. The utility of this strategy is especially apparent in Experiments 3 and 4. In Experiment 3, we showed that the effect could occur for a counterattitudinal issue that was of high personal relevance to students (the implementation of senior comprehensive exams). In Experiment 4, we showed that the effect could occur for a real consumer product about which people had prior attitudes. In each case, participants came to adopt more favorable attitudes, whether they were instructed to think about the information or counterargue it, but these attitudes were more likely to translate into behavioral intentions when they were encouraged to generate negative thoughts during exposure.

The present research expands our knowledge of the consequences that can follow failed counterarguing, and makes important contributions to a small but growing literature on metacognition (Bless \& Forgas, 2000; Nelson \& Narens, 1994; Petty et al., 2002). As demonstrated in Experiment 5, it was not the actual number of negative thoughts of individuals that caused failed counterarguing to lead to more certainty, but rather it was individuals' perceived extent of negative thoughts. Having attempted, but failing, to find fault in a message allows people to infer that they have few reasons against accepting the message. Individuals can say to themselves, "I changed my attitude even though I tried to find faults in the message. I now know I truly have few negative thoughts about the message and my new attitude is a good one." Simply changing one's attitude toward a message, in the absence of an explicit attempt to counterargue, does not give rise to the same thoughts about one's negative thoughts.
Whereas a substantial amount of research and writing has stressed the importance of attitude strength (see Petty \& Krosnick, 1995), research on creating strong attitudes has primarily focused on increasing the extent of issue-relevant elaboration as a means to do this (e.g., Chaiken, 1980; for a review, see Petty et al., 1995). In this regard, the present findings are especially noteworthy, as elaboration was shown to be constant across conditions. In Experiment 3, we found that participants' self-reported elaboration did not differ as a function of instruction set. Although self-reported elaboration has been found to function similar to actual elaboration (e.g., Tormala et al., 2002), to further rule out the possibility of differential elaboration, we conducted a pilot study to examine whether instruction set influenced type or amount of thoughts participants generated in an open-ended thought listing. In this study, 75 participants were randomly assigned to focus either on their thoughts or negative thoughts while reading about Cheer laundry detergent (see Experiment 4). After participants read about the product, we measured their attitudes and attitude certainty. After the completion of these measures, participants completed an open-ended thought listing on which they were told to list all thoughts they had, regardless of the type of thought they were told to focus on. As in the present experiments, attitudes were equivalent regardless of thought instruction, but attitude certainty was greater for those in the directed-negative thinking condition. More important, there was no difference in the valence of thoughts generated or the total number of thoughts generated in the openended thought listing (all $\mathrm{ps}>.40$ ). ${ }^{9}$ Given the convergent evidence (from self-reported elaboration and actual listed thoughts) that elaboration was equivalent in the groups instructed to generate negative thoughts and those undirected in their thinking, the present research provides an entirely new means to create stronger attitudes. That is, challenging message recipients to find fault in the message can strengthen new attitudes in a manner different from that of elaboration, assuming the message is such that people are unable to counterargue it.

In summary, the present experiments contribute to the study of attitude change and persuasion by (a) revealing consequences of failed counterarguing for attitude strength, and (b) highlighting the importance of metacognition. By focusing on these metacognitive processes, we have established a heretofore unrecognized means of creating new strong attitudes.

\section{Boundary Conditions of the Effect}

Although the present research has found that trying but failing to counterargue a message can lead to increased attitude certainty, attempted counterarguing should not always confer this property to attitudes. In fact, as discussed earlier, past research has found that successful counterarguing is typically associated with reductions in attitude change relative to more undirected processing (e.g., Killeya \& Johnson, 1998; Petty \& Cacioppo, 1979). In the next section, we discuss potential boundary conditions of our effect and comment on when attempted counterarguing may influence atti-

\footnotetext{
${ }^{9}$ We examined valence of thoughts by both comparing the raw number of each type of thought (i.e., positive, negative, neutral) between conditions as well as comparing various thought indexes (e.g., positive-negative). None of these comparisons resulted in significant differences in amount of thoughts between directed-negative and undirected participants.
} 
tudes (as in previous research) as opposed to solely influencing certainty.

\section{Strength of Arguments}

In the present research, we developed arguments that elicited relatively few negative thoughts, even when participants were specifically asked to focus on and consider their negative thoughts about the message. In essence, we created "super-strong" arguments. In prior studies examining attitude change, arguments were labeled as strong if they elicited mostly favorable thoughts and few counterarguments when people were simply instructed to think about them (for details on argument strength pretesting procedures, see Petty \& Cacioppo, 1986). In the current research, however, we wanted arguments that were strong enough that people would be generally unable to generate many plausible counterarguments to them even when directed to try. It is not clear that the strong arguments used in prior research would meet this criterion.

Thus, the effects reported in the present studies may only be observed when the arguments are pretested to be especially strong. In fact, in our initial attempts to develop strong arguments, we found ourselves off the mark, and replicated the findings of Killeya and Johnson (1998), wherein people instructed to try and counterargue were able to do so and thus showed resistance to persuasion. It was only through the forging of stronger arguments that we were able to find equivalent attitude change for individuals undirected in their thinking and those instructed to generate negative thoughts. However, it is important to note that this super-strong type of argument is not mythical, and is still likely to be encountered in everyday life, as the arguments used in Experiments 4 and 5 demonstrate. Nevertheless, it seems likely that the more knowledge and confidence people have in their prior attitudes, the less likely it is that persuaders can develop veridical arguments that cannot be counterargued.

\section{Audience Receptivity}

Of course, even if persuaders use the strongest arguments available to them, the audience must presumably still be willing to change. Given that participants can produce resistance responses to very strong arguments toward a consumer product when required to do so (see Experiment 2), we expect that participants often resist strong messages that attack positions to which they are highly committed and are knowledgeable about (see Zuwerink \& Devine, 1996). In such situations, individuals may draw from an entire arsenal of resistance strategies to prevent attitude change, such as attitude bolstering, source derogation, emotional reactions, and/or selective avoidance (Frey, 1986; Gilbert, 1993; Lydon, Zanna, \& Ross, 1988; Pratkanis et al., 1988; Zuwerink \& Devine, 1996).

Furthermore, in the case of very strong prior attitudes based on extensive issue-relevant knowledge, individuals may naturally default to counterarguing on their own accord. That is, for a highly valued attitude, participants may naturally have a goal to resist and direct their thinking toward the generation of counterarguments, even if instructed to simply generate thoughts. If this occurs, then such individuals in an undirected thoughts condition would be very similar to those in a directed counterarguing condition, and thus differences between these conditions would be unlikely. Thus, our findings may be most likely to occur in situations where strong arguments are available to prevent successful counterarguing, where individuals do not initiate other resistance strategies, and where an instruction to counterargue actually has an effect on the amount of attempted counterarguing.

\section{Level of Elaboration}

We think it is likely that the certainty effect we observed is most likely to occur under levels of moderate to high elaboration, as opposed to low levels of elaboration, consistent with prior work on metacognitive processes in persuasion (e.g., Briñol \& Petty, 2003; Tormala et al., 2002). First, the metacognitive process we have discussed relies on individuals being able to conclude that they truly possess few negative thoughts about the message. If individuals were not to take the task seriously, or did not put effort into considering their negative thoughts, they would be unlikely to reach this conclusion about their own negative thoughts. Individuals might think, "I may not have listed any negative thoughts, but I really didn't put much effort into considering my negative thoughts; I might actually have quite a few." Or, they might not have any thoughts about their thoughts, thereby undermining the certainty effect.

On a similar note, if individuals attribute their inability to generate negative thoughts to external factors rather than the validity of their attitude, they may also not demonstrate the certainty effects observed in the present study. For example, if message recipients are distracted when trying to counterargue, they may still fail to counterargue, but they may be unlikely to conclude that they lack negative reactions to the message. That is, they may attribute failure to distraction, not to the validity of their new position. Thus, the reduced counterarguing that distraction induces may lead to enhanced persuasion, but not to increased attitudinal confidence. In fact, if failure to counterargue is associated with distraction, failure may be associated with decreased attitude certainty compared with the same change induced under thought conditions. Specifically, if individuals recognize that the distraction prevented them from counterarguing, they may engage in a sort of metacognitive correction and perceive themselves as having more negative reactions than they listed. This could be investigated in future research.

\section{Extremity Versus Strength}

One interesting question is why a failed attempt to counterargue a message did not produce even more extreme attitudes than undirected thinking. Given the results of Experiment 3, this is unlikely to be due to a ceiling effect. In that study, attitudes in the high-relevance condition that followed failed counterarguing were only at the midpoint of the scale, so there was clearly room for additional change. Although differences in extremity could potentially occur, and are sometimes considered a manifestation of strength (e.g., see Abelson, 1995), we believe that one reason differences in certainty are more likely to result is that the metacognitive process we have discussed is applied after the valence of the attitude has been decided. That is, we think individuals might first decide what their attitude toward the topic is, and then make a judgment about how certain they are in that attitude. Furthermore, the inference that one has few negative thoughts may be applied at the point of deciding the certainty of one's attitude 
rather than at the point of deciding the valence of one's attitude. An individual might think, "I know I have a positive attitude toward this product, and because I have few negative thoughts about this product I am certain my attitude is correct." Although this is only conjecture at this point, this might explain why certainty effects are more likely than extremity effects in this paradigm.

\section{Future Directions}

\section{When Is Counterarguing Futile?}

Some persuaders may view instructing individuals to generate negative thoughts as a gamble with one of two resultant outcomes. One outcome is beneficial: The counterarguing does not inhibit attitude change but, because of the inferences that can be made about individuals' negative thoughts, strengthens the changed attitude. A second outcome is clearly deleterious: The counterarguing leads to less attitude change, backfiring against the persuader. Although we can only speculate at this point, the outcome of counterarguing is likely to hinge on whether people subjectively believe that their counterarguing was unsuccessful or successful. These attributions are likely to depend on factors such as the individuals' ability to actually generate counterarguments, the perceived number and quality of the counterarguments generated, and confidence in the counterarguments generated.

\section{Other Forms of Resistance and Directed Thinking}

The present research examined attitude certainty effects only as a function of directed-negative thinking (i.e., counterarguing). However, there are other means of attempting to resist a message, such as reacting emotionally, source derogation, attitude bolstering, and selective avoidance. It is not clear whether failing to resist a message through these mechanisms would lead to similar effects on attitude certainty. For example, consider an individual who attempts to resist a message by discrediting the source, but subsequently is unable to do so. Resistance of this sort does not address whether the merits of the message are strong or weak. This type of failed resistance seems unlikely to lead an individual to the metacognitive perception that they have no legitimate negative reactions to the message itself. Therefore, failed resistance based solely on attempts at source derogation may not lead to attitude certainty consequences similar to those observed in the present experiments. Thus, contrasting failed resistance through counterarguing with failed resistance through other mechanisms may help us understand when this effect is most likely to occur.

In this article, we focused on attitude change after undirected versus directed-negative thinking. However, thinking can also be directed at finding merit in a message. This notion was entertained in Experiment 1, in which we found that directed-positive thinking did not lead to any more certainty than undirected thinking. However, because the arguments were very strong, participants' attempts to generate positive thoughts were successful. A line of future inquiry could focus on failed favorable thinking compared with undirected thinking. One possibility is that attitude certainty will increase when people fail at their goal of generating favorable thoughts. This might occur if failure leads to metacognitions associated with individuals' perceived positive reactions. For ex- ample, individuals might be exposed to a message that is in favor of using drugs but uses highly specious arguments. If people were encouraged to find merit in the proposal, they may have considerable difficulty in generating positive thoughts. The realization that a person has few positive thoughts might produce a similar increase in strength compared with undirected thinking about the same message. People might reason, "Well, I always thought drugs were bad, and now I know there really isn't anything good about them either!"

\section{Conclusion}

The present research examined the consequences of failed counterarguing on attitude certainty and subsequent ability of attitudes to predict behavioral intentions. On the basis of the five experiments presented, it is clear not only that failing to counterargue a strong message yields new attitudes equivalent to those occurring when a direction to counterargue was not present, but also that failure in one's attempts to counterargue can lead to metacognitions about individuals' own negative thoughts. These metacognitive inferences can lead to more confidently held attitudes that are more predictive of behavioral intentions. Thus, going against intuition, a communicator may sometimes reap benefits from encouraging an audience to find fault in the message, provided resistance of this sort is likely to prove futile.

\section{References}

Abelson, R. P. (1995). Attitude extremity. In R. E. Petty \& J. A. Krosnick (Eds.), Attitude strength: Antecedents and consequences (pp. 215-246). Mahwah, NJ: Erlbaum.

Baron, R. M., \& Kenny, D. A. (1986). The moderator-mediator variable distinction in social psychological research: Conceptual, strategic, and statistical considerations. Journal of Personality and Social Psychology, 51, 1173-1182.

Bassili, J. N. (1996). Meta-judgmental versus operative indexes of psychological attributes: The case of measures of attitude strength. Journal of Personality and Social Psychology, 71, 637-653.

Bless, H., \& Forgas, J. P. (Eds.). (2000). The message within: The role of subjective experience in social cognition and behavior. Philadelphia: Psychology Press.

Briñol, P., \& Petty, R. E. (2003). Overt head movements and persuasion: A self-validation analysis. Journal of Personality and Social Psychology, 84, 1123-1139.

Brehm, J. W. (1966). A theory of psychological reactance. San Diego, CA: Academic Press.

Brehm, J. W. (1972). Responses to loss of freedom: A theory of psychological reactance. Morristown, NJ: General Learning Press.

Cacioppo, J. T., \& Berntson, G. G. (1994). Relationship between attitudes and evaluative space: A critical review with emphasis on the separability of positive and negative substrates. Psychological Bulletin, 115, 401423.

Cacioppo, J. T., \& Petty, R. E. (1979). The effects of message repetition and position on cognitive responses, recall, and persuasion. Journal of Personality and Social Psychology, 37, 97-109.

Chaiken, S. (1980). Heuristic versus systematic information processing in the use of source versus message cues in persuasion. Journal of Personality and Social Psychology, 39, 752-766.

Chaiken, S., Liberman, A., \& Eagly, A. (1989). Heuristic and systematic information processing within and beyond the persuasion context. In J. S. Uleman \& J. A. Bargh (Eds.), Unintended thought (pp. 212-252). New York: Guilford Press. 
Chen, S. \& Chaiken, S. (1999). The heuristic-systematic model in its broader context. In S. Chaiken \& Y. Trope (Eds.), Dual process theories in social psychology (pp. 73-96). New York: Guilford Press.

Fazio, R. H., \& Zanna, M. P. (1978). Attitudinal qualities relating to the strength of the attitude-behavior relationship. Journal of Experimental Social Psychology, 14, 398-408.

Festinger, L. (1950). Informal social communication. Psychological Review, 57, 271-282.

Festinger, L. A. (1954). A theory of social comparison processes. Human Relations, 7, 117-140.

Fishbein, M., \& Ajzen, I. (1975). Belief, attitude, intention, and behavior: An introduction to theory and research. Reading, MA: Addison-Wesley.

Fishbein, M, \& Ajzen, I. (1981). Acceptance, yielding, and impact: Cognitive processes in persuasion. In R. E. Petty, T. M. Ostrom, \& T. C. Brock (Eds.), Cognitive responses in persuasion (pp. 339-359). Hillsdale, NJ: Erlbaum.

Frey, D. (1986). Recent research on selective exposure to information. Advances in Experimental Social Psychology, 19, 41-80.

Gilbert, D. T. (1993). The assent of man: Mental representation and the control of belief. In D. M. Wegner \& J. W. Pennebaker (Eds.), Handbook of mental control (pp. 57-87). Englewood Cliffs, NJ: Prentice Hall.

Gross, S. R., Holtz, R., \& Miller, N. (1995). Attitude certainty. In R. E. Petty \& J. A. Krosnick (Eds.), Attitude strength: Antecedents and consequences (pp. 215-246). Mahwah, NJ: Erlbaum.

Haddock, G., Rothman, A. J., Reber, R., \& Schwarz, N. (1998). Forming judgments of attitude certainty, intensity, and importance: The role of subjective experiences. Personality and Social Psychology Bulletin, 25, 771-782.

Haddock, G., Rothman, A. J., \& Schwarz, N. (1996). Are (some) reports of attitude strength context dependent? Canadian Journal of Behavioral Science, 28, 313-316.

Jacks, J., \& Cameron, K. A. (2003). Strategies for resisting persuasion. Basic \& Applied Social Psychology, 25, 145-161.

Jost, J., Kruglanski, A., \& Nelson, T. (1998). Social metacognition: An expansionist review. Personality and Social Psychology Review, 2, 137-154.

Killeya, L. A., \& Johnson, B. T. (1998). Experimental induction of biased systematic processing: The directed-thought technique. Personality and Social Psychology Bulletin, 24, 17-33.

Krosnick, J. A., \& Abelson, R. P. (1992). The case for measuring attitude strength in surveys. In J. M. Tanur (Ed.), Questions about questions: Inquiries into the cognitive bases of surveys (pp. 177-203). New York: Russell Sage Foundation.

Krosnick, J. A., \& Petty, R. E. (1995). Attitude strength: An overview. In R. E. Petty \& J. A. Krosnick (Eds.), Attitude strength: Antecedents and consequences (pp. 215-246). Mahwah, NJ: Erlbaum.

Kruglanski, A. W. (1996). Motivated social cognition: Principles of the interface. In E. T. Higgins \& A. W. Kruglanski (Eds.), Social psychology: Handbook of basic principles (pp. 493-520). New York: Guilford Press.

Kunda, Z. (1990). The case for motivated reasoning. Psychological Bulletin, 108, 480-498.

Lord, C. G., Ross, L., \& Lepper, M. R. (1979). Biased assimilation and attitude polarization: The effects of prior theories on subsequently considered evidence. Journal of Personality and Social Psychology, 37, $2098-2109$.

Lydon, J., Zanna, M. P., \& Ross, M. (1988). Bolstering attitudes by autobiographical recall: Attitude persistence and selective memory. Personality and Social Psychology Bulletin, 14, 78-86.

McGuire, W. J. (1964). Inducing resistance to persuasion: Some contemporary approaches. In L. Berkowitz (Ed.), Advances in experimental social psychology (Vol. 1, pp. 191-229). New York: Academic.
McGuire, W. J., \& Papageorgis, D. (1962). Effectiveness of forewarning in developing resistance to persuasion. Public Opinion Quarterly, 26, 24 34.

Nelson, T. O., \& Narens, L. (1994). Why investigate metacognition? In J. Metcalfe \& A. Shimamura (Eds.). Metacognition: Knowing about knowing (pp. 1-25). Cambridge, MA: The MIT Press.

Peeters, G., \& Czapinski, J. (1990). Positive-negative asymmetry in evaluations: The distinction between affective and informational negativity effects. European Review of Social Psychology, 1, 33-60.

Petty, R. E., Briñol, P., \& Tormala, Z. L. (2002). Thought confidence as a determinant for persuasion: The self-validation hypothesis. Journal of Personality and Social Psychology, 82, 722-741.

Petty, R. E., \& Cacioppo, J. T. (1979). Effects of forewarning of persuasive intent and involvement on cognitive responses and persuasion. Personality and Social Psychology Bulletin, 5, 173-176.

Petty, R. E., \& Cacioppo, J. T. (1986). The elaboration likelihood model of persuasion. In L. Berkowitz (Ed.), Advances in experimental social psychology (Vol. 19, pp. 123-205). New York: Academic Press.

Petty, R. E., Cacioppo, J. T., \& Haugtvedt, C. (1992). Involvement and persuasion: An appreciative look at the Sherifs' contribution to the study of self-relevance and attitude change. In D. Granberg \& G. Sarup (Eds.), Social judgment and intergroup relations: Essays in honor of Muzafer Sherif (pp. 147-174). New York: Springer/Verlag.

Petty, R. E., Haugtvedt, C. P., \& Smith, S. M. (1995). Elaboration as a determinant of attitude strength: Creating attitudes that are persistent, resistant, and predictive of behavior. In R. E. Petty \& J. A. Krosnick (Eds.), Attitude strength: Antecedents and consequences (pp. 93-130). Mahwah, NJ: Erlbaum.

Petty, R. E., \& Krosnick, J. A. (Eds.). (1995). Attitude strength: Antecedents and consequences. Mahwah, NJ: Erlbaum.

Petty, R. E., \& Wegener, D. T. (1999). The Elaboration Likelihood Model: Current status and controversies. In S. Chaiken \& Y. Trope (Eds.), Dual process theories in social psychology (pp. 41-72). New York: Guilford Press.

Petty, R. E., Wells, G. L., \& Brock, T. C. (1976). Distraction can enhance or reduce yielding to propaganda: Thought disruption versus effort justification. Journal of Personality and Social Psychology, 34, 874884.

Pratkanis, A. R., Greenwald, A. G., Leippe, M. R., \& Baumgardner, M. H. (1988). In search of reliable persuasion effects: III. The sleeper effect is dead. Long live the sleeper effect. Journal of Personality and Social Psychology, 54, 203-218.

Schwarz, N., Bless, H., Strack, F., Klumpp, G., Rittenauer-Schatka, H., \& Simons, A. (1991). Ease of retrieval as information: Another look at the availability heuristic. Journal of Personality and Social Psychology, 61, 195-202.

Shrout, P. E., \& Bolger, N. (2002). Mediation in experimental and nonexperimental studies: New procedures and recommendations. Psychological Methods, 7, 422-445.

Swann, W. B., Pelham, B. W., \& Chidester, T. R. (1988). Change through paradox: Using self-verification to alter beliefs. Journal of Personality and Social Psychology, 54, 268-273.

Tormala, Z. L., \& Petty, R. E. (2002). What doesn't kill me makes me stronger: The effects of resisting persuasion on attitude certainty. Journal of Personality and Social Psychology, 83, 1298-1313.

Tormala, Z. L., Petty, R. E., \& Briñol, P. (2002). Ease of retrieval effects in persuasion: A self-validation analysis. Personality and Social Psychology Bulletin, 28, 1700-1712.

Zuwerink, J. R., \& Devine, P. G. (1996). Attitude importance and resistance to persuasion: It's not just the thought that counts. Journal of Personality and Social Psychology, 70, 931-944. 


\section{Appendix}

\section{Arguments Used in Experiments 1-3}

\section{Arguments in Favor of Relieve Aspirin}

Clinically proven to work in minutes and to outlast other brands of Aspirin by 2 hours

Received a perfect score of 10 on the American Medical Association's efficiency test (where $1=$ poor and $10=$ excellent)

Safe, does not lead to harmful side effects that can occur with other Aspirins (e.g., stomach upset and damage)

\section{Arguments in Favor of Senior Comprehensive Exams}

Increased University Standing: Senior comprehensive exams are a sign to educators, employers, and students of integrated thinking and advanced thinking. The top 10 universities in the nation have all adopted senior comprehensive exams, and the exams will soon be required for a university to receive national accreditation. Adopting the exams means that OSU will continue to be nationally accredited; will continue its tradition of excellence; and will continue to attract top students, faculty, and staff.

Increased Federal Funding: Universities that implement senior comprehensive exams are given additional funding by a new government program that rewards performance-based education. For OSU, this means funds to renovate and improve teaching facilities. For students, this means that at least a 5\% tuition decrease would accompany the passing of the exam proposal. In addition to an immediate $5 \%$ tuition decrease, the government program provides funds to ensure that students' tuition will not be raised for a period of at least 5 years.

Received July 17, 2002

Revision received September 3, 2003

Accepted September 4, 2003

\section{Correction to Chen et al. (2004)}

The article "Self-Verification Motives at the Collective Level of Self-Definition," by Serena Chen, Karen Y. Chen, and Lindsay Shaw (Journal of Personality and Social Psychology, 2004, Vol. 86, No. 1, pp. 77-94), contained an error.

On page 88, under the heading Degree of Correspondence Between Self and Desired Ratings, in the third paragraph, the fourth sentence, "On the other hand, if the self-minus-desired score for this attribute had been positive, the sign would have been left untouched," is misleading and should be ignored. 